\title{
Variations of indicative dates of ice regime on Lake Onego based on ground air temperature
}

\author{
Vyacheslav N. Baklagin \\ Northern Water Problems Institute, Karelian Research Centre, Russian Academy of Sciences, Aleksander Nevsky st. 50, 185030 \\ Petrozavodsk, Republic of Karelia, Russia
}

\begin{abstract}
The paper shows the changes in the dates (complete freeze-up, \pm 5 days $/{ }^{\circ} \mathrm{C}$ and complete ice clearance, \pm 3 days $/{ }^{\circ} \mathrm{C}$ ) of the ice regime in Lake Onego depending on changes in average air temperature within the preceding two-month periods (autumn and spring). The regression equations for their calculation based on previous three- and four-month periods according to the 20002018 data are also provided. Indicative dates of ice regime based on accumulated air temperatures within the ice period of Lake Onego were also established (early formation of ice phenomena, complete freeze-up phase, beginning of the break-up phase and complete ice clearance). Together with the data on expected air temperature above the lake's surface, these dependencies enable us to predict the indicative dates of the ice regime.
\end{abstract}

\section{INTRODUCTION}

Ice cover in lakes has a significant impact on various air-water exchange processes. It reduces the sunlight penetration into water, which is necessary for photosynthesis; it also hinders heat transmission and water oxygenation. Ice conditions on lakes determine the duration of navigation period as well as the possibility of transporting people and/or cargoes over the stable ice (Karetnikov and Naumenko, 2008; Salo and Nazarova, 2011; Assel et al., 2004). The data on ice regime characteristics is applicable to climate models and can be used to predict the periods of freeze-up and break-up phases of lakes (Salo and Nazarova, 2011; Baklagin, 2017). The formation and break-up of ice cover on large lakes depend greatly on the complex of meteorological processes, which occur over the water area of lakes (Salo and Nazarova, 2011; Dibike et al., 2011); therefore, research related to the influence of climate factors on long-term variability of ice regime of lakes is of high interest.

Reduction of ice phenomena duration due to global warming observed over the past few decades is the main tendency in the long-term variability of ice regime of large lakes (Brown and Duguay, 2010; Latifovic and Pouliot, 2007; Efremova et al., 2013; Magnuson et al., 1990). According to Livingstone (1997), the ice of large lakes serves as a sensitive indicator of climate change that is even more reliable than air temperature.

With the water surface area of $9720 \mathrm{~km}^{2}$, Lake Onego is one of the biggest lakes in Europe. Identifying the patterns of ice regime formation of Lake Onego is of great importance for issues connected with organizing water transport between such settlements as Petrozavodsk, Medvezhyegorsk, Kondopoga, Povenets, Vytegra, Voznesenye, as well as on White Sea-Baltic Canal and Volga-Baltic Canal (Salo and Nazarova, 2011).

Long-term variability of ice regime of large lakes on the territory of the Republic of Karelia, including Lake Onego, has been described by Efremova et al. (2013). The authors observed that during the years 1950-2009, the duration of ice phenomena on Lake Onego reduced by more than 20 days. Identified variability patterns of air temperature influence on the formation and break-up of ice cover show that for Lake Onego, in particular, freeze-up dates are most accurately indicated by November-December average air temperature, and break-up dates by that of April-May. Furthermore, a $\pm 1{ }^{\circ} \mathrm{C}$ fluctuation of average air temperature leads to a $\pm 4-6$ days shift of the freeze-up dates and a $\pm 3-4$ days shift of the break-up dates (Efremova et al., 2013). It is important to note that these results were derived from visual ice cover data at the observation stations of the Russian meteorological service and that they are relevant for small lakes, which can visually inspected by the observers. In case of Lake Onego, the observation is focused on the ice cover condition of Petrozavodsk Bay. Its surface area is less than $2 \%$ of the total surface area of Lake Onego, which is not sufficient for estimating the indicative periods of the ice regime.

Long-term variability of the ice regime on Lake Onego was described by Salo and Nazarova (2011) based on air observations of ice for the period of 1955-1990 performed by air research office of the North-West, the Federal Service for Hydrometeorology and Environmental Monitoring. Based on the data, the correlation between indicative periods, the duration of ice phenomena, air temperature (Weather station Petrozavodsk), and NAO (Northern Atlantic Oscillation) index was traced.

It is worth noting that the data obtained from ice surface mapping of Lake Onego used in the study (Salo and Nazarova, 2011) lacks sufficient time interval for proper evaluation of indicative dates of ice regime and the analysis of chronological ice coverage progress (510 air observations within the period of ice formation). 
The maximum alternation rate of ice coverage of Lake Onego per 24 hours for the years $2000-2018$ is $62.5 \%$ (registered by MODIS sensor, from $8^{\text {th }}$ to $9^{\text {th }}$ January, 2016).

More reliable information on the ice cover of lakes is obtained from satellite observations (Karetnikov and Naumenko, 2008; Assel et al., 2004; Baklagin, 2018). For the last few years, daily satellite surveys of the Earth using various ranges (visual, infrared, microwave), have collected large amounts of data including the data about snow and ice cover of the planet. For this reason, it is necessary to update previous studies (Salo and Nazarova, 2011; Efremova et al., 2013) based on present satellite data and to confirm previously identified correlations. Besides that, we need to analyze the potential influence of temperature conditions and some other meteorological factors (such as wind and snow cover depth) on ice cover formation and break-up on Lake Onego, since these issues have not been fully described in the available studies.

The purpose of this study is to identify statistical correlations between meteorological parameters and the ice regime characteristics of Lake Onego calculated on the basis of satellite data within the years 2000-2018.

\section{METHODS}

\section{Identification of the ice regime in Lake Onego}

Given the possible quick changes in areas of ice phenomena on Lake Onego (up to $63 \%$ per 24 hours), the ice regime characteristics of Lake Onego for the years 20002018 were calculated on the basis of daily time series of ice coverage obtained from satellite observations. In this study we used satellite data provided by National Aeronautics and Space Administration, USA, NASA (device MODIS - The Moderate Resolution Imaging Spectroradiometer, with a spatial resolution of $250 \mathrm{~m}$ ), National Snow and Ice Data Center, NSIDC (4-6 km), Center for Satellite Applications and Research, NOAA NESDIS (4$6 \mathrm{~km}$ ). The technique described by Bakalgin (2018) was used to develop daily time series of ice cover of Lake Onego on the basis of these data series with minimizing faulty proportion while identifying ice cover (Fig. 1).

For the purposes of comprehensive assessment of the change of ice cover during the period of ice phenomena, sums of daily values of ice coverage for each period of ice phenomena were calculated using the formula: $\sum i c e=\sum_{(\mathrm{k}=1)}^{\mathrm{n}} i c e_{k}$, where ice $_{k}$ is ice coverage value (ice cov-

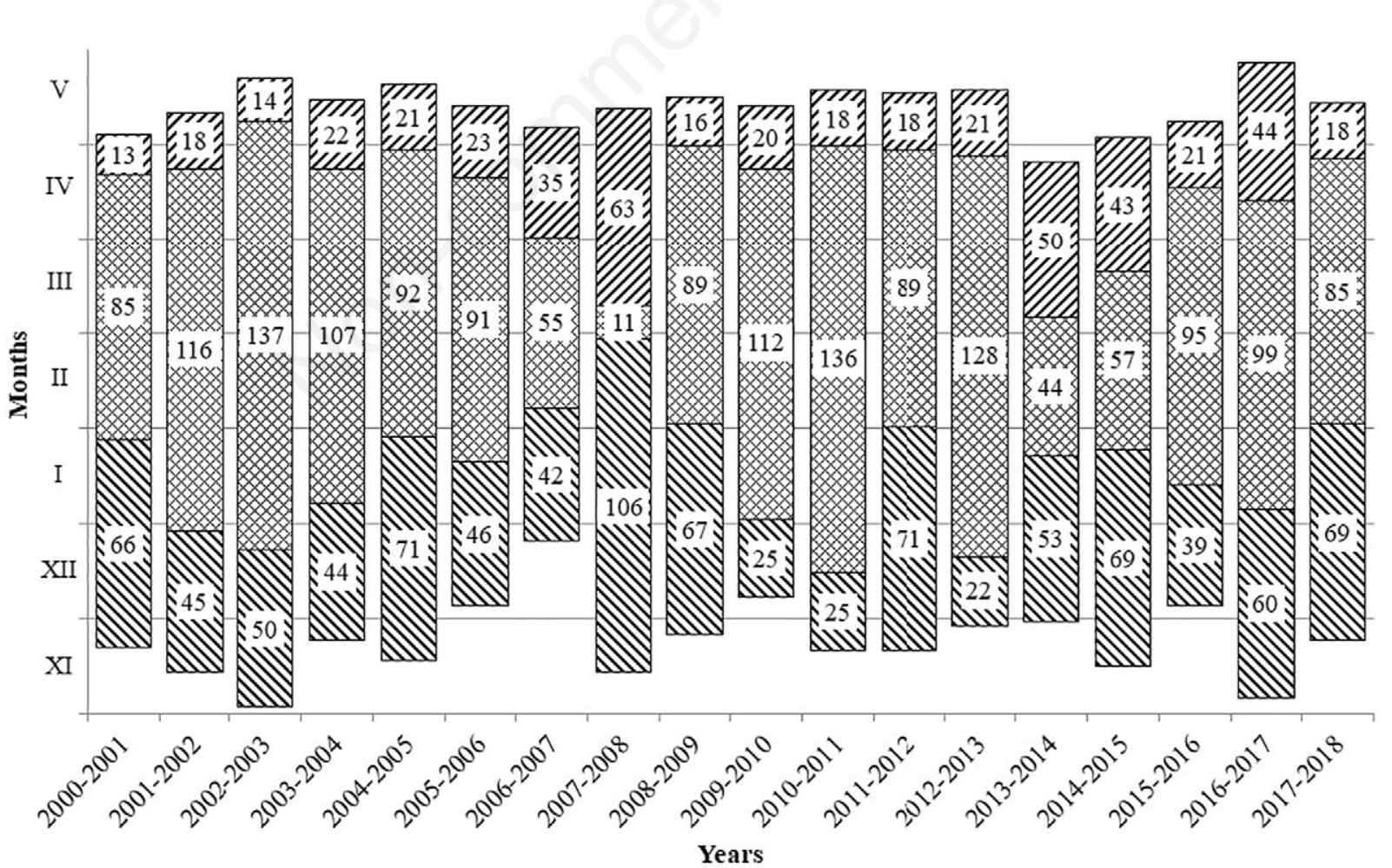

$\triangle 1 \otimes 2 \square 3$

Fig. 1. Dates of the beginning and the ending of phases and the duration (number of days) of ice freezing (1), complete freeze-up (2) and break-up (3) on Lake Onego for the period 2000-2018. 
erage is defined as the ratio of the ice cover area to the total lake area) in $k$-day of the period of ice phenomena, $n$-duration of the period of ice phenomena. Values $\sum i c e$ and RICI, i.e. the calculation technique that was used to estimate the ice regime of Lake Ladoga (Karetnikov and Naumenko, 2008) are similar, since values RICI for each year were obtained by normalizing of value $\sum$ ice to mean value $\overline{\sum i c e}$ for multiyear period. However, in this study there is no need in normalizing values $\sum i c e$ for identification of statistical correlation.

\section{Estimation of meteorological conditions above Lake Onego}

In this study we used daily data of mean air temperature, precipitation, and snow-cover depth for the years 2000-2017 from meteorological observation points near Petrozavodsk and Vytegra provided by All-Russia Research Institute of Hydrometeorological Information World Data Centre (RIHMI-WDC) (http://meteo.ru). Data on daily mean air temperature and wind speed for the years 2000-2018 from meteorological observation points near Petrozavodsk, Medvezhyegorsk, Vytegra, and Pudozh were provided by National Oceanic and Atmospheric Administration, USA, NOAA (NCDC NOAA) (ftp://ftp.ncdc.noaa.gov/pub/data/noaa/).

Meteorological conditions above Lake Onego were estimated by averaging of parameters measured at four observation points around the lake (Fig. 2): near Petrozavodsk (22820), Medvezhyegorsk (22721), Vytegra (22837), and Pudozh (22831) (with index of the World Meteorological Organization, WMO). Several observation points for estimating meteorological parameters were chosen to cover the variability of climatic conditions caused by the large dimensions of Lake Onego (from north to south, $248 \mathrm{~km}$; from west to east, $96 \mathrm{~km}$ ). For instance, the average air temperature according to RIHMIWDC and NCDC NOAA for the period of 2000-2017 at Medvezhyegorsk is $3.11^{\circ} \mathrm{C}$, in Petrozavodsk $-3.89^{\circ} \mathrm{C}$, and in Vytegra $-4.06^{\circ} \mathrm{C}$.

The dates of the beginning and end of the periods of accumulated positive temperatures $\sum T_{+}$and negative temperatures $\sum T$ - were derived from the condition: $\sum_{t_{1}}^{t_{2}} \mid \mathrm{T}_{t}$ $\rightarrow$ max, where $t_{1}, t_{2}$ are the dates of beginning and end of the periods during the current hydrological year, $T_{\mathrm{t}}$ is the average air temperature for the date $t$.

\section{Method of determining the indicative dates of ice regime based on accumulated air temperatures}

This study assumes that accumulated negative air temperatures over the lake required for beginning ice phenomena formation $\sum T_{\text {freezing }}$ and the complete freeze-up on the lake $\sum T_{i c e}$, probably depend on thermal reserve of the lake before the beginning of the cold season in question.
This thermal reserve of the lake depends on accumulated positive air temperatures $\sum T_{+}$of previous warm season. Moreover, accumulated negative air temperatures over the lake required for the beginning break-up $\sum T_{\text {breaking }}$ and the complete ice clearance on the lake $\sum T_{\text {free }}$, depend on accumulated negative air temperatures $\sum T$ - of previous cold season. In the study, regression analysis was used to determine the dependencies of the accumulated air temperatures required for changing the phases of ice regime (indicative date) on accumulated air temperatures of previous period, i.e. the accumulated air temperatures required for changing the phases of ice regime (indicative date) is function from accumulated air temperatures of previous period $\sum T_{\text {ind date }}\left(\sum T\right)$. We can calculate the indicative date of the ice regime date $_{\text {ind }}$ based on a forecast of air temperatures for a period (for example, a week) and the calculated value $\sum T_{\text {ind date }}\left(\sum T_{\text {freezing }}, \sum T_{\text {ice }}, \sum T_{\text {breaking, }}\right.$, $\left.\sum T_{\text {free }}\right)$. The indicative date of ice regime is determinate:

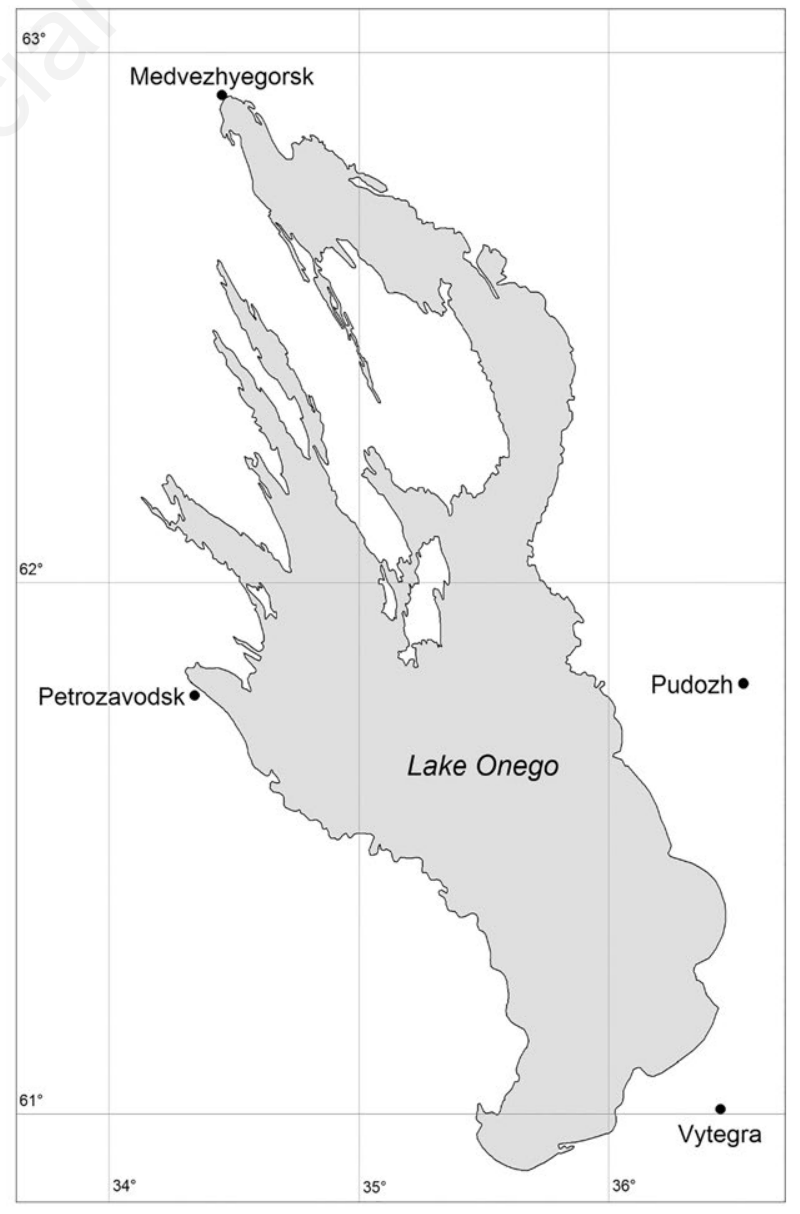

Fig. 2. The location of meteorological observation points on the coast of Lake Onego. 
date $_{\text {ind }}=$ date $_{\text {cur }}+x$

where date $_{\text {cur }}$ is the current date; $x$ is the duration of the period from current date to the indicative date of the ice regime (days). Value $x$ can be determined based on the condition:

$\sum T_{\text {ind date }} \approx \sum T_{\text {cur date }}+\sum_{j=1}^{x} T_{j}$,

where $\sum T_{\text {cur date }}$ ) is the accumulated air temperatures for period from the date of air temperature transition over $0^{\circ} \mathrm{C}$ to current date $\left({ }^{\circ} \mathrm{C}\right) ; j$ is the counting number of days from current date; $T_{j}$ is the daily predicted air temperature of $j^{\text {th }}$ days $\left({ }^{\circ} \mathrm{C}\right)$. The method of calculation resides in searching the value $x$ where eq. 2 will be true.

\section{RESULTS}

For the analyzed range of years 2000-2018, the duration of ice phenomena period varied from 132 to 203 days with the average value of 171 days (from November to May), coefficient of variation is $10 \%$, complete freeze-up period - from 11 to 137 days, with the average value of 90 days, coefficient of variation is $36 \%$.

Statistical characteristics of accumulated positive and negative air temperatures over Lake Onego are repre- sented on Fig. 3. For the years 2000-2018, the accumulated sums of positive air temperatures over the Lake Onego $\sum T_{+\max }$ ranged from $1932^{\circ} \mathrm{C}$ to $2527^{\circ} \mathrm{C}$, absolute values of negative air temperatures $\sum T_{-\max }$ from $553^{\circ} \mathrm{C}$ to $1520^{\circ} \mathrm{C}$. It is noteworthy that the average daily air temperature over Lake Onego in the years 2000-2018 was $0.9^{\circ} \mathrm{C}$ higher than in 1936-1999 (data provided by RIHMI-WDC) (Tab. 1). In addition, this increase in the average air temperature was mainly caused by frequent warm winters over the last years. Over the years 20002018, the cold seasons differed from one another in terms of temperature conditions more considerably (variation coefficient of $\sum T_{-\max } 32 \%$ ) than the warm seasons (variation coefficient of $\sum T_{+\max } 7 \%$ ).

According to the calculations for the years 2000-2018, the dates of air temperature transition over $0^{\circ} \mathrm{C}$ to negative values over Lake Onego were within the range from $14^{\text {th }}$ October to $25^{\text {th }}$ November, and to positive values - from $4^{\text {th }}$ March to $21^{\text {st }}$ April. The average period with positive air temperatures (warm season) lasted 220 days, and with negative air temperatures (cold season) 144 days.

Correlation analysis showed, that the following values: Eice, the duration of freeze-up $D$ (days) and the total period of ice phenomena $L$ (days) on the Lake Onego have close correlation (L to a lesser extent) with annual average air temperature over the lake $\bar{T}$ (paired correlation coeffi-
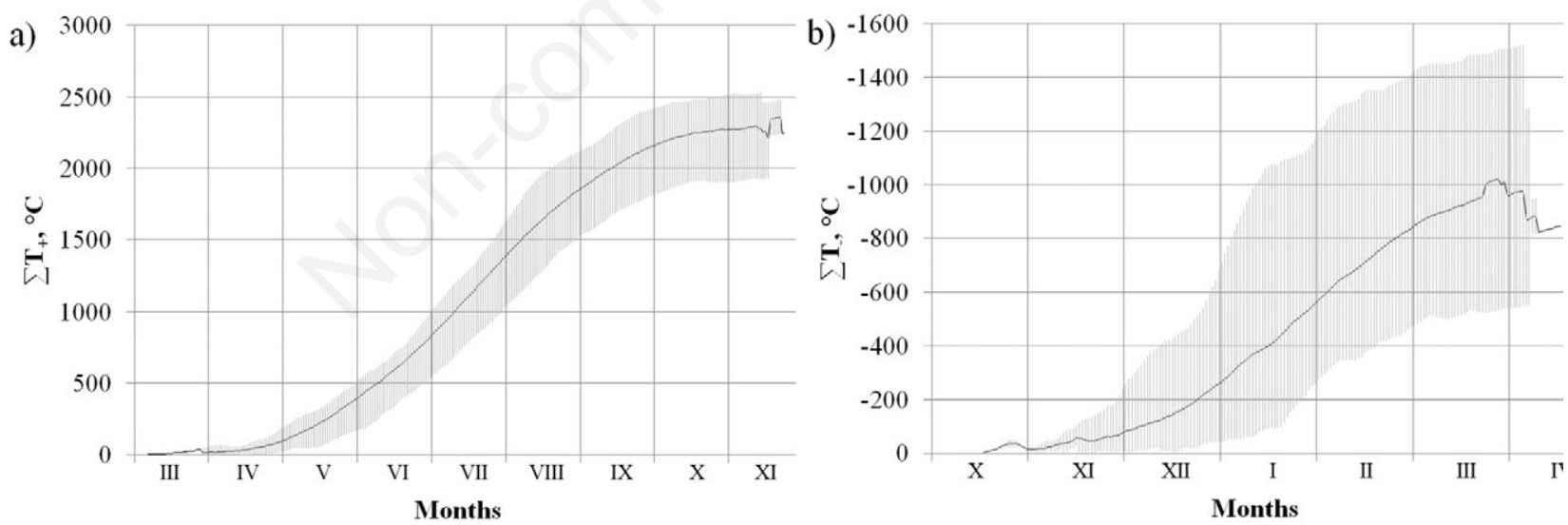

Fig. 3. Integral curves of positive (a) and negative (b) air temperatures over Lake Onego with the range of sample for the period $2000-2018$.

Tab. 1. Temperature conditions over Lake Onego at different time periods.

\begin{tabular}{lccc} 
Period & \multicolumn{2}{c}{ Average air temperature $\left({ }^{\circ} \mathrm{C}\right)$} & Difference $\left({ }^{\circ} \mathrm{C}\right)$ \\
& $\mathbf{1 9 3 6 - 1 9 9 9}$ & $\mathbf{2 0 0 0 - 2 0 1 8}$ & 0.9 \\
Year & 2.7 & 3.6 & 0.8 \\
Warm season & 9.6 & 10.4 & 1.4 \\
\hline Cold season & -8.2 & -6.8 &
\end{tabular}


cients $-0.89,-0.83$ and -0.50 , respectively). The regression analysis revealed polynomial relationships of $\sum i c e$ and $D$ with annual average air temperature over the lake $\bar{T}$ :

$\sum$ ice $=-0,548 \cdot \bar{T}^{2}-17,566 \cdot \bar{T}+188,649\left(R^{2}=0.8 ; \mathrm{P}<0.05\right)$

$D=-3,894 \cdot \bar{T}^{2}-3,782 \cdot \bar{T}+157,531 \quad\left(R^{2}=0.7 ; \mathrm{P}<0.05\right)$

\section{Updating air temperature - ice regime relationships}

The starting date of ice phenomena formation on Lake Onego was calculated by multiple regression from monthly average air temperatures:

$D_{\text {freezing }}=0,249 \cdot \bar{T}_{X I I}{ }^{2}-0,061 \cdot \bar{T}_{X I}{ }^{2}-0,444 \cdot \bar{T}_{X}^{2}+$

$4,253 \cdot \bar{T}_{I X}{ }^{2}+3,579 \cdot \bar{T}_{X I I}+1,974 \cdot \bar{T}_{X I}+4,122 \cdot \bar{T}_{X}-$

$79,643 \cdot \bar{T}_{I X}+422,458 \quad\left(R^{2}=0.81 ; \mathrm{P}<0.05\right) \quad$ (eq. 5)

where $D_{\text {freezing }}$ is the duration of the period from $1^{\text {st }}$ October to the beginning of ice phenomena formation, (days); $\bar{T}_{i}$ is the average air temperature of $i^{\text {th }}$ month over the lake in ${ }^{\circ} \mathrm{C}$.

Strong correlation $(r=0.76 ; \mathrm{P}<0.05)$ was also identified between the average air temperature for a two-month period - from November to December $\bar{T}_{X I-X I I}$ and the dates of ice complete freeze-up on the lake for 2000-2018.

The dependency of changing of these dates from the value $\bar{T}_{X I-X I I}$ was obtained (Fig. 4). The slope factors of dependences are coherent with the results of a similar study on the ice regime of Lake Onego for the period of 1950-2009 (Efremova et al., 2013) (Tab. 2). The average air temperature over the lake from December to January $\left(\bar{T}_{X I I-I}\right)$ had the strongest correlation $(r=0.88 ; \mathrm{P}<0.05)$ with the ice complete freeze-up on Lake Onego for the period of 2000-2018. (Tab. 2). However, values $\bar{T}_{X I-X I I}$ were used to define relationships in the study by Efremova et al. (2013).

Considering air temperatures of a 4-month period (October-January) instead of a 3-month period (October-De-
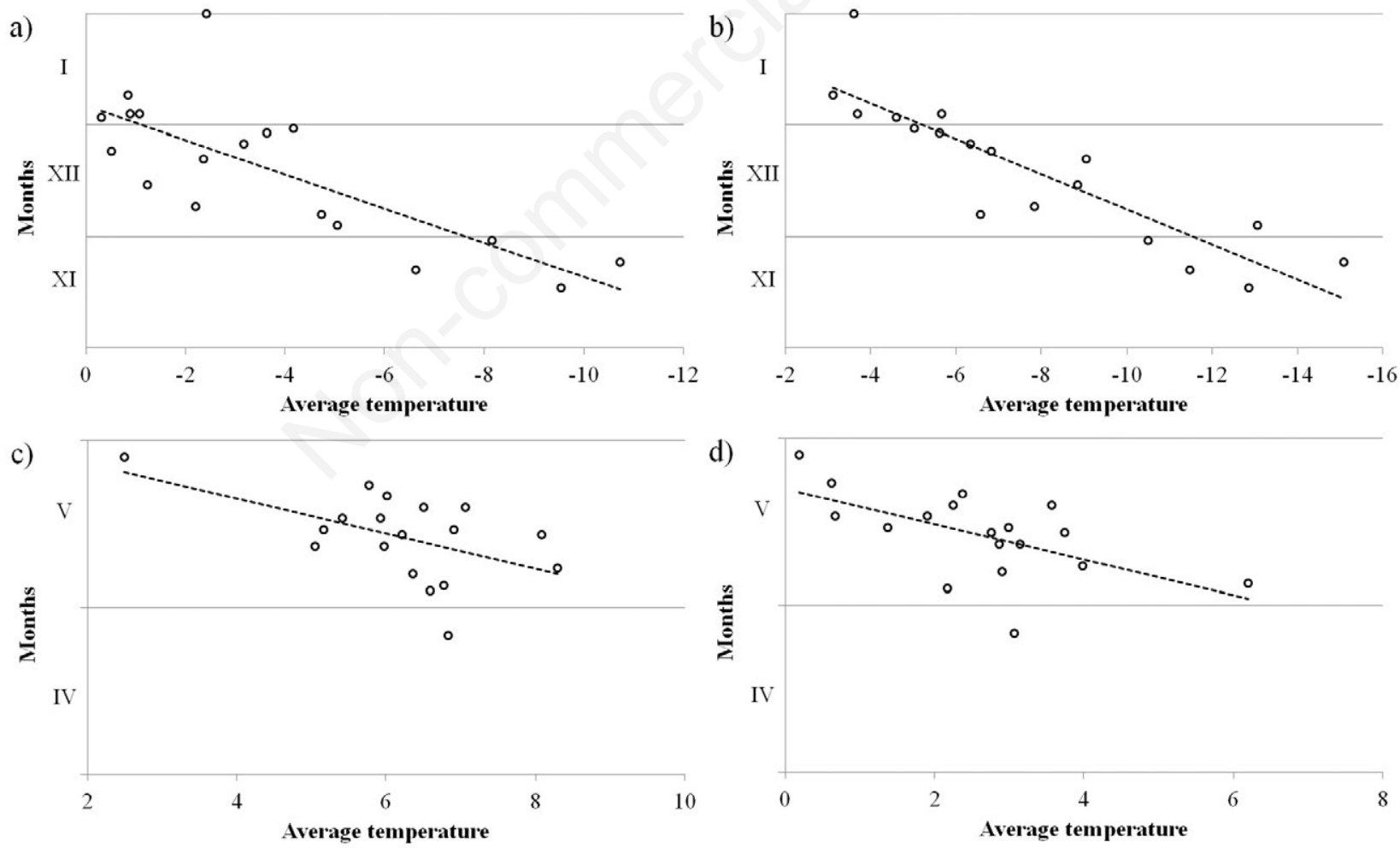

$\circ 1--2$

Fig. 4. Dependences of indicative dates of ice regime on Lake Onego on air temperature for the years 2000-2018, where a) dates of complete freeze-up depending on the average air temperature for period from November to December; b) dates of complete freeze-up depending on the average air temperature for period from December to January; c) dates of complete ice clearance depending on the average air temperature for period from April to May; d) dates of complete ice clearance depending on the average air temperature for April. 1, actual values; 2 linearly regression function. 
cember) as used by Salo and Nazarova (2011) for estimating the complete freeze-up on Lake Onego for 1955-1990, as well as applying the polynomial multiple regression helped to improve the explanatory power of the regression model ( $R^{2}$ rose from 0.74 to 0.89 ):

$D_{\text {ice }}=0,380 \cdot \bar{T}_{I}^{2}+0,073 \cdot \bar{T}_{X I I}^{2}+0,267 \cdot \bar{T}_{X I}^{2}+$

$0,692 \cdot \bar{T}_{X}^{2}+10,295 \cdot \bar{T}_{I}+3,466 \cdot \bar{T}_{X I I}+$

$2,109 \cdot \bar{T}_{X I}-3,881 \cdot \bar{T}_{X}+187,491 \quad\left(R^{2}=0.89 ; \mathrm{P}<0.05\right)$

where $D_{\text {ice }}$ is the duration of the period from 1 st October to the beginning of complete freeze-up phase, days.

The beginning of ice cover break-up could be determined by air temperature from January to March:

$D_{\text {break }}=-0,089 \cdot \bar{T}_{I I I}^{2}-0,385 \cdot \bar{T}_{I I}^{2}-0,130 \cdot \bar{T}_{I}^{2}-$

$2,344 \cdot \bar{T}_{I I I}-8,701 \cdot \bar{T}_{I I}-4,412 \cdot \bar{T}_{I}-27,842$

$\left(R^{2}=0.63 ; \mathrm{P}<0.05\right)$

where $D_{\text {break }}$ is the duration of the period, starting with $1^{\text {st }}$ of March, until the beginning of ice cover break-up, days.

A lower negative correlation $(r=-0.52 ; \mathrm{P}<0.05)$ was found between the dates of the complete ice clearance on Lake Onego and the April-May average air temperature $\bar{T}_{I V-V}$. Considering April air temperatures only slightly strengthened the correlation (Tab. 2).

The best multiple regression model for estimating the dates of complete ice clearance included air temperatures from March to May:

$D_{\text {free }}=0,328 \cdot \bar{T}_{V}^{2}-0,096 \cdot \bar{T}_{I V}^{2}-0,126 \cdot \bar{T}_{I I I}^{2}-$

$6,910 \cdot \bar{T}_{V}-2,925 \cdot \bar{T}_{I V}-2,370 \cdot \bar{T}_{I I I}+79,620$,

$\left(R^{2}=0.71 ; \mathrm{P}<0.05\right)$

where $D_{\text {free }}$ is the duration (in days) of the period from $1^{\text {st }}$ April to complete ice clearance.

Averages of the absolute deviations of the calculated values from the actual values were as follows: determining the date of the beginning of the ice formation: 3-4 days; determining the date of freeze-up phase: 4-5 days; determining the date of the beginning break-up phase: 23 days; determining the date of complete ice clearance on the lake: 7-8 days (Fig. 5).

\section{The effect of the accumulated positive and negative air temperatures on ice regime}

The values $\sum T_{\text {ice }}, \sum T_{\text {free }}$ for the years 2000-2018 showed a wide variation (Tab. 3 ). No correlation was detected between $\sum T_{i c e}$ and $\sum T_{+_{\max }}(r=-0.01)$.

$\sum T_{\text {ice }}$ and $\sum T_{\text {freezing }}$ had strongest correlations (correspondingly, $r=0.70 ; \mathrm{P}<0.05$ and $r=-0.57 ; \mathrm{P}<0.05$ ) with the accumulated positive air temperatures for the last 55 days of the warm season (before the transition to negative values), $\sum T_{55}$.

On the basis of regression analysis, equations were obtained connecting $\sum T_{\text {freezing }}$ and $\sum T_{55}$, and $\sum T_{\text {ice }}$ and $\sum T_{55}$ for Lake Onego:

$$
\begin{gathered}
\sum T_{\text {freezing }}=7,195 \cdot 10^{-5} \cdot \sum T_{55}{ }^{2}-0,092 \cdot \sum T_{55}-7,768 . \\
\left(R^{2}=0.33 ; \mathrm{P}<0.05\right)
\end{gathered}
$$

The analysis connecting $\sum T_{-\max }$ and $\sum T_{\text {free }}, \sum T_{-\max }$ and $\sum T_{\text {-break }}$ showed a close statistical correlation (by the Cheddok scale), with pair correlation coefficient between $\sum T_{-\max }$ and $\sum T_{\text {free }}$ and $\sum T_{-\max }$ and $\sum T_{- \text {break }}$ equal to $-0,75$ and $-0,78$, respectively.

Regression analysis connecting $\sum T_{-\max }$ and $\sum T_{- \text {break }}$, and $\sum T_{-\max }$ and $\sum T_{\text {free }}$ showed the following results:

$$
\begin{aligned}
& \sum T_{- \text {break }}=-4,8389 \cdot 10^{-7} \sum T_{-\max }{ }^{3}- \\
& 0,0016 \cdot \sum T_{-\max }{ }^{2}-1,6623 \cdot \sum T_{-\max }-527,852
\end{aligned}
$$$$
\left(R^{2}=0.72 ; \mathrm{P}<0.05\right) \quad(\text { eq. } 11)
$$

$$
\begin{aligned}
& \sum T_{\text {free }}=-1,9775 \cdot 10^{-7} \cdot \sum T_{-\max }{ }^{3}- \\
& 0,0008 \cdot \sum T_{-\max }^{2}-1,1202 \cdot \sum_{-\max }-268,835 \\
& \quad\left(R^{2}=0.66 ; \mathrm{P}<0.05\right)
\end{aligned}
$$

The mean values of the absolute deviations of accumulated air temperatures from the actual values were as

Tab. 2. Changes in indicative dates of the ice regime (complete freeze-up and complete ice clearance dates) on Lake Onego per $\pm 1^{\circ} \mathrm{C}$ change in average air temperature in different periods.

\begin{tabular}{lccc} 
Period & Pair correlation coefficient & Date changes per $\pm 1^{\circ} \mathrm{C}$ change in mean air temperature, days \\
& & $\mathbf{1 9 5 0 - 2 0 0 9}$ & $\mathbf{2 0 0 0 - 2 0 1 8}$ \\
November-December & 0.76 & $\pm 4-6$ & \pm 5 \\
December-January & 0.88 & - & \pm 5 \\
\hline April-May & -0.52 & $\pm 3-4$ & \pm 3 \\
April & -0.59 & - & \pm 3 \\
\hline
\end{tabular}


follows: $5-6^{\circ} \mathrm{C}$ at the beginning of the period of formation of ice phenomena; $-38-39^{\circ} \mathrm{C}$ at the time of complete freeze-up; $12-13^{\circ} \mathrm{C}$ at the beginning of the period of ice break-up; $-27-28^{\circ} \mathrm{C}$ at the moment of complete ice clearance of the lake from ice.

\section{DISCUSSION}

Calculation results of average durations of warm and cold seasons corresponds to the results of the research (Nazarova, 2013). It is important to note that the average duration of ice phenomena period of Lake Onego (171 days) is longer than the period of negative air temperatures over the lake.

Prediction of indicative dates of the ice regime of Lake Onego using the regression equations (5)-(8) for calculations $D_{\text {freezing }}, D_{\text {ice }}, D_{\text {break }}$, and $D_{\text {free }}$ is not justified because, in most cases, the predicted date precedes the periods used as input data for which average air temperatures are calculated. For example, the average statistical date for the complete freeze-up phase on Lake Onego over the period 2000-2018 is January $16^{\text {th }}$, but in some years the complete
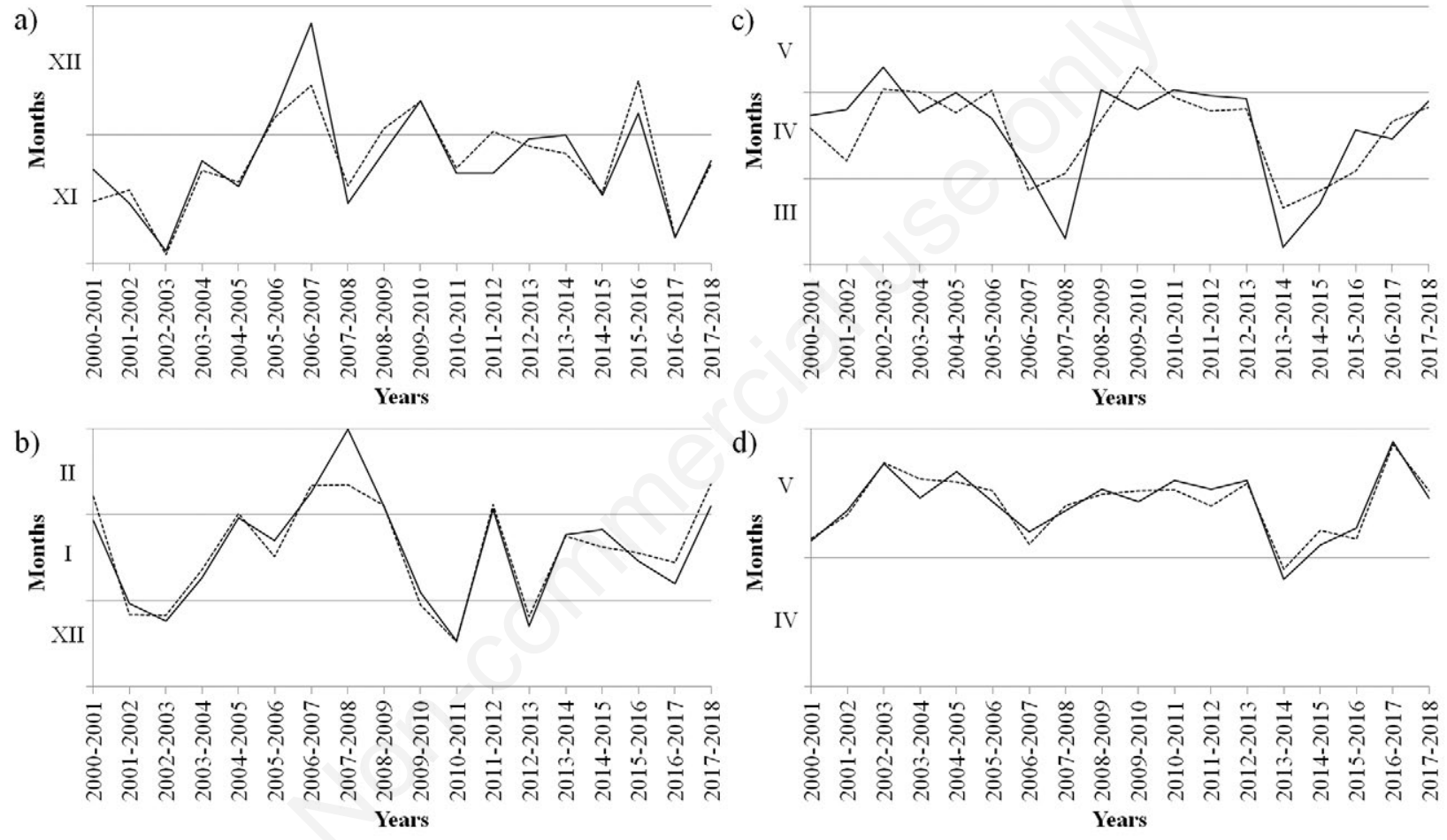

$$
-1 \cdots 2
$$

Fig. 5. Actual (1) and predicted on the basis of the provided regression models (2) indicative dates of the beginning of the ice phenomena formation (a); complete freeze-up phase (b); beginning of ice cover break-up (c); and complete clearing of ice (d) on Lake Onego for the period 2000-2018.

Tab. 3. Accumulated air temperatures over the water area of Lake Onega within the indicative dates of the ice regime for different time periods. Data for 1955-1990 are from the study by Salo and Nazarova (2011).

\begin{tabular}{|c|c|c|}
\hline \multirow[t]{2}{*}{ Values } & \multicolumn{2}{|c|}{ Periods } \\
\hline & 1955-1990 & 2000-2018 \\
\hline \multicolumn{3}{|l|}{ Accumulated air temperatures over the waters of Lake Onego } \\
\hline At the beginning of the formation of ice cover $\sum T_{\text {freezing }}\left({ }^{\circ} \mathrm{C}\right)$ & - & $-43--15$ \\
\hline At the complete freeze-up phase $\sum T_{i c e}\left({ }^{\circ} \mathrm{C}\right)$ & $-490--290$ & $-500--275$ \\
\hline At the beginning of break-up phase $\sum T_{\text {break }}\left({ }^{\circ} \mathrm{C}\right)$ & - & $0-115$ \\
\hline At the moment of complete ice clearance on the lake $\sum T_{\text {free }}\left({ }^{\circ} \mathrm{C}\right)$ & $200-310$ & $87-294$ \\
\hline
\end{tabular}


freeze-up phase occurred in mid-late December (Fig. 1), while the equation for calculating the $D_{i c e}$ value includes the average value of January air temperatures, which obviously do not affect the $D_{i c e}$ value. The strong correlation $(0.88)$ in this case can probably be explained by the reverse effect of the ice cover on the air temperature over its surface.

The calculated intervals of the values $\sum T_{\text {ice }}, \sum T_{\text {free }}$ for the period of 2000-2018 were consistent with the results by Salo and Nazarova (2011) (Tab. 3). Probably strong correlations between $\sum T_{i c e}$ with $\sum T_{55}$ and $\sum T_{\text {freezing }}$ with $\sum T_{55}$ is caused by the fact that high positive air temperatures over Lake Onego in autumn (on the average during the period 2000-2018 September-October) inhibit water cooling in the lake, keeping the heat accumulated during the summer. Therefore, the bigger value of accumulated negative air temperatures $\sum T_{-}$is required for further drop of the water surface temperature to $0^{\circ} \mathrm{C}$ and for ice formation. The described phenomenon can occur in autumn in case of a sudden winter which is followed by transition from moderate positive temperatures $\left(5-10^{\circ} \mathrm{C}\right)$ to negative ones, omitting small positive temperatures $\left(0-5^{\circ} \mathrm{C}\right)$.

The obtained equations for calculating $\sum T_{\text {freezing }}, \sum T_{\text {ice }}$, $\sum T_{- \text {break }}, \sum T_{\text {free }}$ taking into account data on expected air temperature, can potentially be used to predict the indicative dates of the ice regime of Lake Onego.

It should also be noted that this study notes a shift in the period affecting the date of formation of ice cover of Lake Onego for the years 2000-2018, a month ahead comparing with the periods in question (Efremova et al., 2013; Salo and Nazarova, 2011) (three months and two months, respectively). Perhaps this phenomenon is associated with the late dates of the freeze-up phase on Lake Onego in 2000-2018 (on average - January $16^{\text {th }}$ ) than in previous years, as a result of this tendency towards a reduction in duration of the period of ice phenomena on large lakes due to global warming (Brown and Duguay, 2010; Latifovic and Pouliot, 2007; Efremova et al., 2013, Magnuson et al., 1990). In addition, as already noted, calculations of the characteristics of the ice regime of Lake Onego in this paper (Efremova et al., 2013) were made on the basis of observations of the condition of the ice cover of the Petrozavodsk Bay, which due to its morphological structure is covered with ice much earlier than the water area of the lake as a whole. Moreover, significant differences in the values of the lower limit of the interval of value $\sum T_{\text {free }}$ (Tab. 3) is due to the presence of abnormally low $\sum T_{+}$values in 2013 and 2014, when a complete ice clearance of Lake Onego was recorded ( $\sum T_{\text {free }}$, respectively, $87^{\circ} \mathrm{C}$ and $92^{\circ} \mathrm{C}$ ). In these years, abnormally warm winters preceded the break-up phase - the accumulated negative air temperatures during the cold season $\sum T_{-\max }$ had minimum values for the years $2000-2018$ (about $555^{\circ} \mathrm{C}$ ), with an average value of $-970^{\circ} \mathrm{C}$ over this period.

\section{CONCLUSIONS}

The dependences of the indicative dates of the ice regime of Lake Onego on air temperature are generally consistent with the results obtained earlier in (Efremova et al., 2013; Salo and Nazarova, 2011). However, in 20002018 there was one-month ahead shift in the period affecting the date of the formation of ice cover in comparison with the second half of the 20th century, considered in the studies by Efremova et al. (2013) and Salo and Nazarova, 2011). This indicates climate change in recent decades, which contributes to the late winter onset and, as a consequence the shift in the freeze-up dates, which is consistent with the concept of global warming. Therefore, it can be concluded that the models of the formation of the ice cover of Lake Onego presented in papers (Efremova et al., 2013; Salo and Nazarova, 2011) require some adjustment to be applicable nowadays.

The equations for calculating the indicative dates of the ice regime (5)-(8) are hardly applicable for forecasting, but can be used for diagnostic purposes, for example, to re-design the long-term time series of the characteristics of the ice regime of Lake Onega based on the available daily data on air temperature. This is particularly true for the first half of the 20th century, when there are only fragmentary data on the condition of the ice cover of the Petrozavodsk Bay of Lake Onego and rare air observations due to the lack of appropriate technical means (satellite observations). The indicative dates of the ice regime of Lake Onego are potentially predictable on the basis of the equations derived in the paper. This may be of practical use in planning the navigation period and the organization of waterways.

\section{ACKNOWLEDGMENTS}

The study was fulfilled with the financial support of the Grant of the President of the Russian Federation MK3379.2018.5.

\section{REFERENCES}

Assel R, Drobot S, Croley II TE, 2004. Improving 30-day Great Lakes ice cover outlooks. J. Hydrometeorol. 5:713-717.

Baklagin VN, 2017. Selection of parameters and architecture of multilayer perceptrons for predicting ice coverage of lakes. Ekol. Bratislava 36:226-234.

Baklagin VN, 2018. Variability of the Lake Onega ice coverage in the period 2000-2018 according to the satellite data. Ice Snow 58:552-558.

Brown LC, Duguay CR, 2010. The response and role of ice cover in lake-climate interactions. Prog. Phys. Geog. Earth Environ. 34:671-704.

Dibike Y, Prowse T, Saloranta T, Ahmed R, 2011. Response of 
Northern Hemisphere lake-ice cover and lake-water thermal structure patterns to a changing climate. Hydrol. Process. 25:2942-2953.

Efremova TV, Palshin NE, Zdorovennov RE, 2013. Long-term characteristics of ice phenology in Karelian lakes. Est. J. Earth Sci. 62:33-41.

Karetnikov SG, Naumenko MA, 2008. Recent trends in Lake Ladoga ice cover. Hydrobiology 599:41-48.

Latifovic R, Pouliot D, 2007. Analysis of climate change impacts on lake ice phenology in Canada using the historical satellite data record. Remote Sens. Environ. 106:492-507.

Livingstone DM, 1997. Break-up of alpine lakes as proxy data for local and regional mean surface air temperatures. Climatic Change 37:407-439.

Magnuson JJ, Benson BJ, Kratz TK., 1990. Temporal coherence in the limnology of a suite of lakes in Wisconsin, U.S.A. Freshwater Biol. 23:145-159.

Nazarova LE, 2013. Climate change and fluctuations in the Karelian-Kola region. Environment. Technology. Resources. Proceedings 9th Int. Scientific Practical Conf. 1:53-56.

Salo YA, Nazarova LE, 2011. [Multiannual variability of the
Onega Lake ice regime in conditions of variability of the regional climate].[Article in Russian]. Processes Russian Geogr. Soc. 143:50-55.

Corresponding author: slava.baklagin@mail.ru

Key words: Ice regime; Lake Onego; air temperature.

Received: 2 April 2019.

Accepted: 14 June 2019.

This work is licensed under a Creative Commons Attribution NonCommercial 4.0 License (CC BY-NC 4.0).

${ }^{\circ}$ Copyright: the Author(s), 2019

Licensee PAGEPress, Italy

Advances in Oceanography and Limnology, 2019; 10:8198

DOI: 10.4081/aiol.2019.8198 